\title{
Global energy accumulation and net heat emission
}

\section{Bo Nordell* and Bruno Gervet}

Department of Civil and Environmental Engineering

Luleå University of Technology

SE-97187 Luleå, Sweden

E-mail: bon@1tu.se

E-mail: brunogervet@ hotmail.fr

*Corresponding author

\begin{abstract}
The increase in the global air temperature is an inadequate measure of global warming, which should rather be considered in terms of energy. The ongoing global warming means that heat has been accumulating since 1880 in the air, ground and water. Before explaining this warming by external heat sources, the net heat emissions on Earth must be considered. Such emissions from, e.g., the global use of fossil fuels and nuclear power, must contribute to global warming. The aim of this study is to compare globally accumulated and emitted heat. The heat accumulated in the air corresponds to $6.6 \%$ of global warming, while the remaining heat is stored in the ground (31.5\%), melting of ice $(33.4 \%)$ and sea water $(28.5 \%)$. It was found that the net heat emissions from 1880-2000 correspond to $74 \%$ of the accumulated heat, i.e., global warming, during the same period. The missing heat $(26 \%)$ must have other causes, e.g., the greenhouse effect, the natural variations in the climate and/or the underestimation of net heat emissions. Most measures that have already been taken to combat global warming are also beneficial for the current explanation, though nuclear power is not a solution to (but part of) the problem.
\end{abstract}

Keywords: global warming; heat accumulation; heat emission; thermal pollution.

Reference to this paper should be made as follows: Nordell, B. and Gervet, B. (2009) 'Global energy accumulation and net heat emission', Int. J. Global Warming, Vol. 1, Nos. 1/2/3, pp.378-391.

Biographical notes: Bo Nordell is a Professor of Water Resources Engineering at the Luleå University of Technology (LTU) in Sweden. His expertise is in seasonal thermal energy storage, in which he has worked for 30 years. $\mathrm{He}$ heads LTU's research group on renewable energy since 2000.

Bruno Gervet, from Chamonix in France, made his MSc thesis on global warming at LTU, Sweden.

\section{Introduction}

Global mean temperatures have been compiled based on long-term air temperature measurements (NCDC-NOAA, 2007). These temperatures (found in Figure 1) are separated into a monthly Sea Surface Temperature (SST) and a monthly Land Area Temperature (LAT). The global mean temperature is the area-weighted mean of LAT and 
SST. In 1880 , SST was $15.9^{\circ} \mathrm{C}$ and LAT was $8.6^{\circ} \mathrm{C}$, with a global mean of $13.6^{\circ} \mathrm{C}$. Until 2000 , SST had increased by $0.5^{\circ} \mathrm{C}$ and LAT, by $1.2^{\circ} \mathrm{C}$. The corresponding global mean temperature increase in $1880-2000$ was $0.7^{\circ} \mathrm{C}$. However, the global mean air temperature increase is an inadequate measure of global warming and, independent of what causes global warming, it should be considered in terms of energy (Pielke et al., 2004; Pielke, 2005). Here, global warming is considered the global energy accumulation in air, ground and water since 1880 .

Figure 1 The global LAT and SST from 1880-2000 (see online version for colours)

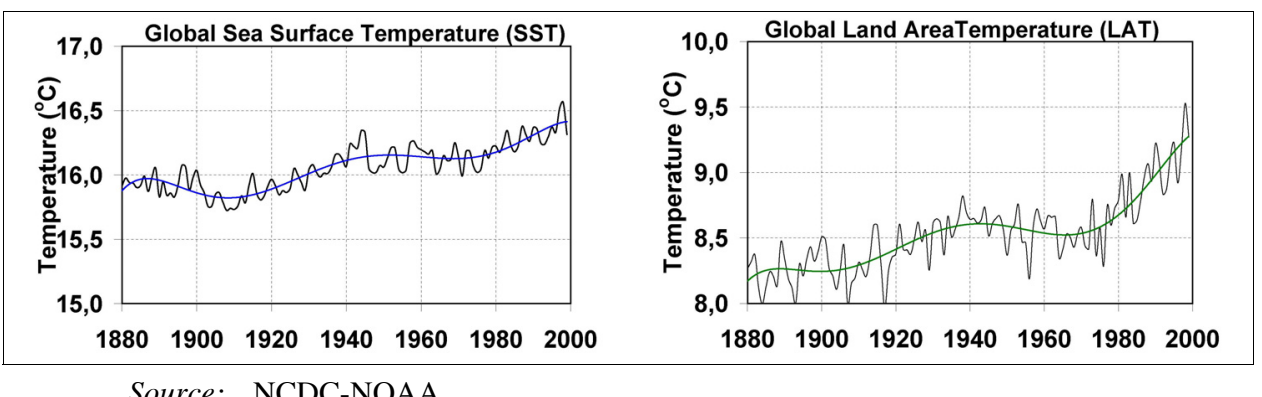

Before explaining global warming by extraterrestrial heat sources, the net heat emissions on Earth should be considered. Emissions such as heat dissipation from the global use of fossil fuels and nuclear power must contribute to global warming. It is a common opinion that the heat emitted by anthropogenic systems is insignificant because it is very small compared to solar energy input. However, this solar energy input does not cause any warming over the year as long as the planet is in thermal balance. Therefore, it is not relevant to compare the net heat emissions with the flux of energy from the sun. What really matters is the change in the energy balance and the occurring net heat emission must, to some extent, contribute to global warming.

Another common idea is that the net heat emissions would be emitted to space. This is partly true only in some rare cases when net heat is emitted at a high temperature. In most cases, however, net heat emissions mean that low-temperature waste heat is dumped into sea water or the atmosphere or heat leakage from buildings is transferred to the surrounding air or ground. When this net heat is mixed with large recipients, it means that it very soon will be at the ambient temperature.

In the current study, accumulated and emitted heat were estimated and compared.

\section{Global heat accumulation}

The methods used to calculate the temperature increase and the subsequent heat accumulation in the ground and air are described in Appendix A. The performed calculations include the period from 1880-2000. 


\subsection{Heat accumulation in the ground}

As a result of the increased air temperature, the ground surface has also warmed up and heat has been conducted into the ground. The performed calculations, which are described in Appendix A, show that the ground heat accumulation rate was relatively linear until 1960, when it began accelerating. Since the late 1990s, it has exceeded the geothermal heat flow, indicating a net heat inflow from the surface into the ground. The heat content of the ground increased by $23.4 \mathrm{kWh} \mathrm{m}^{-2}$ from 1880 to 2000 . This heat conduction into the ground occurs neither in permafrost areas, defined as perennial ground ice, nor on glacier ice or icings (National Snow and Ice Data Center - NSIDC, 2007a). Such areas, which are affected differently by global warming, are included in the melting of ice and contributes to the rise in the sea level. The glaciated areas $\left(0.1610^{14} \mathrm{~m}^{2}\right)$ (Singh and Singh, 2001) and permafrost areas in the world $\left(0.3010^{14} \mathrm{~m}^{2}\right)$ thus reduce the total land area $\left(1.5 \cdot 10^{14} \mathrm{~m}^{2}\right)$ affected by heating to $1.02 \cdot 10^{14} \mathrm{~m}^{2}$. The total ground heat accumulation since 1880 then becomes $23.9 \cdot 10^{14} \mathrm{kWh}$.

\subsection{Heat accumulation in air}

The heat accumulation in air (moist static energy) was estimated separately for sea and land. Hence, different mean air temperatures over sea and land were considered. The total heat accumulation in the air is $5.010^{14} \mathrm{kWh}$, of which $44.6 \%$ is distributed over the land area. The performed calculations are described in Appendix A.

\subsection{Heat accumulation in water}

The heat accumulation in ocean water was estimated from the Global Sea Level Rise (GSLR), compiled by the Permanent Service for Mean Sea Level (PSMSL, 2007). The GSLR is a result of various factors, e.g., the inflow of water from melting glaciers and the thermal expansion of the warmer water, which are both a result of global warming, i.e., indirect anthropogenic effects. Examples of direct anthropogenic effects (Harvey, 2000) since 1880 are the increasing water vapour content of the air, the permanent removal of water from aquifers, deforestation and the loss of soil moisture, reduction in the extent of wetlands, storage behind dams, deep infiltration behind dams, deep infiltration of irrigation water and ocean sedimentation. An important factor might be the ocean sedimentation rate, which increases with an increasing global mean temperature (Broecker et al., 1958).

Measurements show that the GSLR has been relatively steady since 1880 , rising $0.18 \mathrm{~m}$ until 2000 (PSMSL, 2007). Its constant increase indicates that it is not directly a result of global energy consumption, which is far from linear (Figure 2). The values based on the processes mostly responsible for the increase in GSLR mass, from melting land ice and volume increase due to thermal expansion, give a considerably lower sea level change (Miller and Douglas, 2006), suggesting that most of the rise is caused by direct anthropogenic effects. 
Figure 2 The annual world consumption of commercial nonrenewable energy, 1880-2000 (see online version for colours)

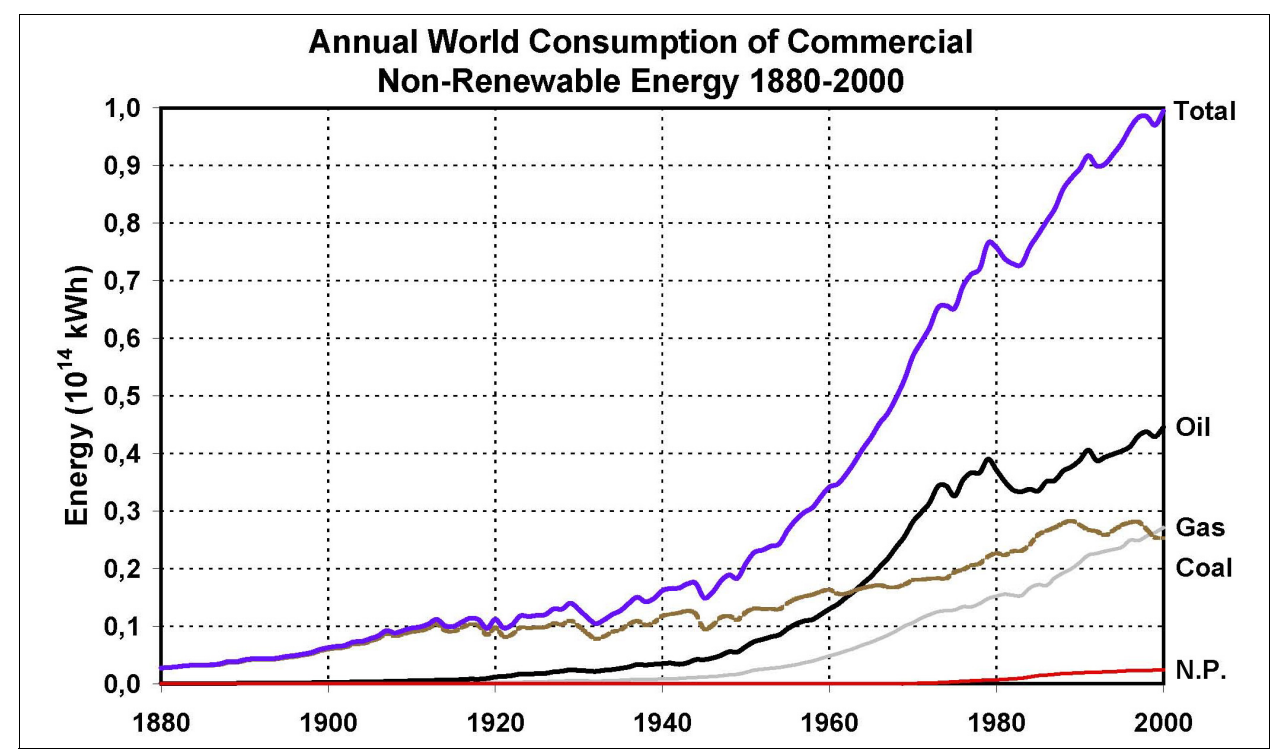

Source: CDC (2007)

There are various data regarding the contribution of thermal expansion to the 20th century sea level rise. The most commonly suggested thermal volume expansion rate is presently $0.5 \mathrm{~mm}$ per year (Church et al., 2001; Antonov et al., 2002). Recent studies show considerably lower values (Ishii et al., 2003) and it is reported that the ocean water has been cooled for several years (Lyman et al., 2006). Satellite measurements show that large-scale El Niño-like ocean temperature fluctuations occurred between 1955 and 1995 (Ishii et al., 2003). Such fluctuations and the recently reported ocean temperature decrease is a result of large-scale and long-cycled ( $\sim 15$ years) ocean circulation, leading to the melting of sea ice and the subsequent cooling of the water. Based on the temperature fluctuations between 1955 and 1995, with three maximum and two minimum values during the period, a thermal expansion rate of $0.02 \mathrm{~mm} \mathrm{year}^{-1}$ was estimated (Ishii et al., 2003). Since this expansion, i.e., $1 \mathrm{~mm}$ over the last 50 years, is a result of global warming, the corresponding previous expansion until 1955 should be insignificant. Assuming that this sea water heating occurred in the top $1000 \mathrm{~m}$ of the ocean with a salinity of $35 \mathrm{ppm}$, this $1 \mathrm{~mm}$ thermal expansion corresponds to $21.6 \cdot 10^{14} \mathrm{kWh}$ of heat.

Recent estimates of the total sea level rise due to the melting of small glaciers and Greenland is about $60 \mathrm{~mm}$. Here, this contribution is estimated to about $50 \mathrm{~mm}$ until 2000. The main uncertainty is whether the ice mass of Antarctica is decreasing or increasing, i.e., causes the sea level to rise or not (Harvey, 2000). If the mass of ice on Antarctica increases, the total melt heat will be correspondingly less. The energy required to melt glaciers and permafrost, totalling a $50 \mathrm{~mm}$ sea level rise, is $16.810^{14} \mathrm{kWh}$.

The total area of sea ice is $19.9 \cdot 10^{12} \mathrm{~m}^{2}$, of which $14.8 \cdot 10^{12} \mathrm{~m}^{2}$ is floating on the northern hemisphere. The estimated annual melting in 1980-2000 was $0.38 \% \pm 0.02 \%$ on the northern hemisphere and $0.02 \% \pm 0.48 \%$ (NSIDC, 2007b) on the southern hemisphere. During the same period, the total thinning of the $3 \mathrm{~m}$-thick ice was estimated 
at 4\% (Johannessen et al., 2003). Here, the values for the northern hemisphere are used, while the very uncertain values for the southern hemisphere are disregarded. The resulting annual melting of $258 \mathrm{~km}^{3}$ of sea ice requires $0.2210^{14} \mathrm{kWh}_{\text {year }}{ }^{-1}$ during 1980-2000. The melted sea ice during the last 120 years is considered proportional to the energy consumption during the same period (see Figure 2), resulting in the melting of $10^{4} \mathrm{~km}^{3}$ of sea ice and a corresponding heat absorption of $8.510^{14} \mathrm{kWh}$. The melted sea ice, which is often considered not to influence the sea level, will actually have a volume that is $2.6 \%$ greater than that of the ice and contribute slightly to the sea level rise (Noerdlinger and Brower, 2008). The total heat accumulation in ocean water during $1880-2000$, i.e., by the heating of sea water and the melting of land and sea ice, then adds up to $46.9 \cdot 10^{14} \mathrm{kWh}$.

The global heat accumulation in the air, ground and water during $1880-2000$ is thus $75.810^{14} \mathrm{kWh}\left(27.310^{21} \mathrm{~J}\right)$. This heat is distributed in the air $(6.6 \%)$, ground $(31.5 \%)$, water $(28.5 \%)$ and melting of land and sea ice (33.3\%) according to Figure 3. It is noticeable that the heat content in air only corresponds to $6.6 \%$ of global warming.

Figure 3 The total global warming, i.e., heat accumulation in air, ground and water/ ice since 1880 (see online version for colours)

Note: The total heat accumulation is $75.8 \cdot 10^{14} \mathrm{kWh}\left(27.3 \cdot 10^{21} \mathrm{~J}\right)$.

\section{Global net heat generation}

The major natural heat source is geothermal heat flow, but heat is also generated by volcanic eruptions, earthquakes and meteorites, among others. Non-natural heat sources include the global use of fossil fuels, nuclear power and deforestation. Heat emissions from nuclear bomb tests and conventional bombs also add to the net heat generation.

\subsection{Geothermal heat flow}

Global heat flow data are collected by the International Heat Flow Commission (IHFC, 2007). The compiled mean geothermal heat flow (Pollak et al., 1993) is $0.065 \mathrm{~W} \mathrm{~m}^{-2}$ for the continents and $0.101 \mathrm{~W} \mathrm{~m}^{-2}$ for the oceans. Its variation is a result of the composition and thickness of the upper part of the crust. The total geothermal heat flow during the last 120 years is $486 \cdot 10^{14} \mathrm{kWh}\left(175 \cdot 10^{21} \mathrm{~J}\right)$. This energy is considerably greater than the global energy consumption during the same period and is given as a reference value to other net heat sources, though it does not contribute to global warming. 


\subsection{Commercial energy}

The world's consumption of commercial nonrenewable energy from 1880 to 2000 (CDIAC, 2007; EIA, 2007) is shown in Figure 2. It has been steadily increasing and was smaller than the preceding years, only in 1975 and 1981. The use of renewable energy has also increased, though it represents less than $5 \%$ of the world's energy consumption.

The total commercial energy consumption from $1880-2000$ is $38.5 \cdot 10^{14} \mathrm{kWh}$ $\left(13.9 \cdot 10^{21} \mathrm{~J}\right)$. All this energy dissipates into heat when consumed and must contribute to the heating of our planet. A useful key value is that the global energy consumption in 2000 was approximately $10^{14} \mathrm{kWh}\left(0.36 \cdot 10^{21} \mathrm{~J}\right)$.

\subsection{Volcanoes and earthquakes}

The energy released through volcanic eruptions comes from several sources, though the most significant (and the one considered here) is the thermal energy of volcanic eruptions. Based on the number and magnitudes of eruptions (Simkin and Siebert, 1994), the thermal energy released from a few large volcanic eruptions during the last 120 years was estimated to $3.95 \cdot 10^{14} \mathrm{kWh}$.

An average of 1.4 million earthquakes occurs each year on Earth. Most are small and disregarded, while larger earthquakes with a magnitude of 8-9 are included in this net heat calculation. The energy released in an earthquake is given by the Gutenberg-Richter (Gutenberg and Richter, 1956) magnitude-energy relation. The United States Geological Survey (USGS, 2007) Frequency of Occurrence of Earthquakes was used to estimate the total energy dissipation $\left(2.7 \cdot 10^{14} \mathrm{kWh}\right)$. A few earthquakes occurring once a century or so would result in greater heat emissions than all others combined. Such quakes are not included here, but must be considered in similar studies on geological timescales.

\subsection{Nuclear bomb tests and conventional bombs}

More than 2000 nuclear tests, atmospheric and underground, were carried out in 1945-1998. Though nuclear explosions have a great power, the released energy was small because of its short duration. The performed nuclear tests (Lawson, 1998) released a total of $6.64 \cdot 10^{12} \mathrm{kWh}$ of heat.

The energy released by conventional bombs was also investigated. The bombs and weapons used during the Second World War released a net heat of $6.7 \cdot 10^{9} \mathrm{kWh}$. The corresponding value for the Gulf War was $9.8 \cdot 10^{7} \mathrm{kWh}$. Therefore, wars do not directly mean any significant net heating, though their consequences do. During the Gulf War, 700 oil wells were set on fire and $190 \mathrm{Mm}^{3}$ of oil burned for 8 months (GulfLINK, 2007). This meant that $1.9 \cdot 10^{12} \mathrm{kWh}$ of heat was added to the atmosphere. It is estimated that $10^{13} \mathrm{kWh}$ of energy was released by the bombs in all the wars (Stockholm International Peace Research Institute - SIPRI, 2007) during the last 120 years.

\subsection{Noncommercial fossil fuel consumption}

The fossil fuel consumed outside the energy market is not included in the global energy statistics. Examples of such noncommercial energy are flares at gas and oil fields, fires at coal fields and underground fires in coal mines and petroleum products that are not used 
in energy production, e.g., in the production of plastics. Deforestation and the amount of heat released from such sources were evaluated by Gervet (2007). This reference also contains working material used to determine other net heat sources.

\subsection{Gas flaring}

The flaring of associated gas was a common industry practice in the early 'decades' of oil production, when there were virtually no gas markets or concerns regarding the environment or the rational use of hydrocarbon resources. Gas flaring in Africa alone is presently equivalent to half of that continent's power consumption. Fewer than 20 countries account for more than $85 \%$ of gas flaring and venting. The magnitude of this problem is underlined by the World Bank's The News Flare (Global Gas Flaring Reduction - GGFR, 2007; WB, 2007), which is devoted to reducing global gas flaring. The energy released by gas flaring during the last 120 years approximately corresponds to the annual global energy consumption in 1999 , i.e., $0.9 \cdot 10^{14} \mathrm{kWh}$.

\subsection{Underground coal fires}

Hundreds of coal fields are burning out of control around the world. Some of the oldest and largest coal fires occur in China, the USA and India. In China alone, such fires annually consume 20 metric tonnes of coal (Stracher and Taylor, 2004). Those burning underground can be difficult to locate and are not included in this net heat estimation. Fires in coal fields worldwide consume 1307 million tonnes of coal that emits $8.8 \cdot 10^{12} \mathrm{kWh}$ of heat.

Another net heat source is oil used for the production of plastics. This oil, which is not included in the energy statistics, will sooner or later be burnt or decomposed. The net heat generation from the use of crude oil in plastic making is roughly $0.4 \cdot 10^{14} \mathrm{kWh}$ from 1939 to 2000 .

\subsection{Deforestation}

The annual deforestation rate is $200 \mathrm{~km}^{2}$ since 2000 , before which it was even greater. Most of the deforestation occurs in tropical forests, mainly in Africa. Since 1850, $11.1 \mathrm{Mkm}^{2}$ has been deforested, totalling 282800 million tonnes of wood. Assuming that the deforested wood were burnt or decomposed, the net heat generation since 1880 has been $8.2 \cdot 10^{14} \mathrm{kWh}$.

\subsection{Nuclear power}

Until 2000, the accumulated amount of electricity produced by nuclear power is approximately $0.410^{14} \mathrm{kWh}$. Since $78 \%$ of the world's nuclear park has an efficiency of $33 \%$, the resulting heat emission from nuclear power plants is $0.810^{14} \mathrm{kWh}$.

Waste heat from nuclear power plants means a very small share of the total heat emissions, but locally, it means a large impact on the recipient. As an example, Sweden's nuclear power plants generate $70 \mathrm{TWh}$ of electricity, which consequently means that $140 \mathrm{TWh}$ of waste heat is produced and dumped into the sea water. This amount of heat is $40 \%$ greater than the annual space heating demand of all buildings in Sweden. It is also 
a fact that algae blooming in Swedish costal waters occur where this waste heat is dumped. This algae blooming is generally blamed on global warming and this is most likely true, since waste heat is part of the problem.

A summary of the net heat generation is given in Table 1 . The main part $(\sim 70 \%)$ of the net heat emissions $\left(38.5 \cdot 10^{14} \mathrm{kWh}\right)$ results from the commercial consumption of oil, gas, coal and nuclear power, while other nonrenewable heat sources total $10.410^{14} \mathrm{kWh}$ and miscellaneous heat sources (volcanoes, earthquakes, etc.) produce $6.8 \cdot 10^{14} \mathrm{kWh}$. The global net heat generation between 1880 and 2000 was $55.7 \cdot 10^{14} \mathrm{kWh}\left(20.1 \cdot 10^{21} \mathrm{~J}\right)$.

Table 1 Global net heat generation, 1880-2000

\begin{tabular}{|c|c|c|c|}
\hline \multirow[b]{2}{*}{ Commercial nonrenewable energy consumption } & \multicolumn{2}{|c|}{ Heat generation } & \multirow{2}{*}{$\frac{\text { Ratio }}{(\%)}$} \\
\hline & $\left(10^{14} \mathrm{kWh}\right)$ & $\left(10^{18} \mathrm{~kJ}\right)$ & \\
\hline Crude oil & 15.2 & 5.48 & 20.1 \\
\hline Gas & 6.9 & 2.49 & 9.1 \\
\hline Coal & 16.0 & 5.76 & 21.1 \\
\hline Nuclear & 0.4 & 0.14 & 0.5 \\
\hline Total & 38.5 & 13.87 & 50.8 \\
\hline \multicolumn{4}{|l|}{ Other nonrenewable heat sources } \\
\hline Gas flaring & 0.9 & 0.32 & 1.2 \\
\hline Coal fires & 0.1 & 0.03 & 0.1 \\
\hline Deforestation & 8.2 & 2.95 & 10.8 \\
\hline Production of plastics & 0.4 & 0.14 & 0.5 \\
\hline Waste heat from nuclear power & 0.8 & 0.29 & 1.1 \\
\hline Total & 10.4 & 3.42 & 13.7 \\
\hline \multicolumn{4}{|l|}{ Miscellaneous heat sources } \\
\hline Volcanoes & 4.0 & 1.42 & 5.2 \\
\hline Earthquakes & 2.7 & 0.97 & 3.6 \\
\hline Nuclear tests & 0.1 & 0.03 & 0.1 \\
\hline Wars (bombs) & 0.1 & 0.04 & 0.1 \\
\hline Total & 6.8 & 2.46 & 9.0 \\
\hline Total: Net heat emission & 55.7 & 20.1 & 73.5 \\
\hline Total: Accumulated heat & 75.8 & 27.3 & 100.0 \\
\hline Missing heat & 20.1 & 7.2 & 26.5 \\
\hline
\end{tabular}

As shown by Figure 4, the global net heat generation explains almost $74 \%$ of global warming. The missing heat could be a result of natural variations in solar intensity, atmospheric forcing due to $\mathrm{CO}_{2}$ emissions into the atmosphere and/or the underestimation of net heat emissions. 
Figure 2 Global warming and heat sources (see online version for colours)

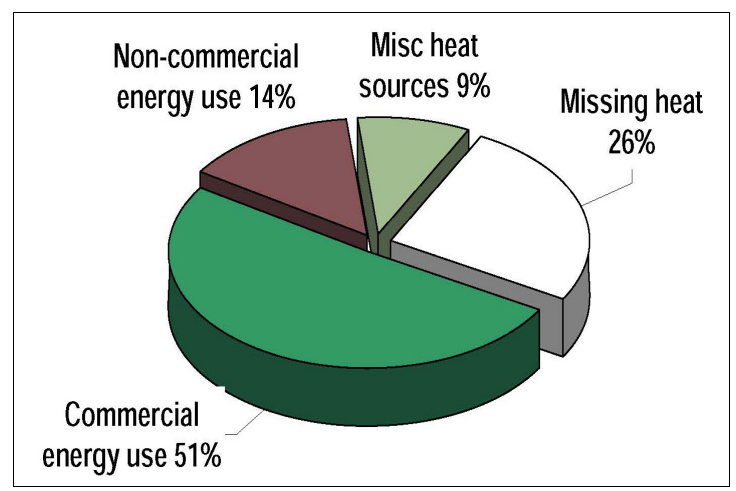

Notes: The circle represents the global warming, i.e., the global heat accumulation for $1880-2000$. It is seen that $74 \%$ of global warming is a result of heat emissions, while the remaining $26 \%$ (missing heat) must have other causes.

\section{Concluding remarks}

Independent of what causes global warming, it should be considered in terms of accumulated energy. The performed estimations of global heat accumulation in the air, ground and global net heat emissions only include the years from 1880 to 2000.

The data used in estimating global heat accumulation in the air, ground and melting of land ice are relatively reliable, while the melting of sea ice might be overestimated. The main uncertainty concerns sea temperature increase, which means that sensible heat accumulation in sea water might be underestimated. It was found that the air only contains $6.6 \%$ of the globally accumulated heat, of which $45 \%$ is distributed over the land area, though it accounts for about $30 \%$ of Earth's total area. The remaining heat is accumulated in the ground $(31.5 \%)$, sea water $(28.5 \%)$, melting of sea ice $(11.2 \%)$ and melting of land ice $(22.2 \%)$ (Figure 4$)$.

The melting of ice has absorbed $33.4 \%$ of the total global warming. The heat stored by sea water, the melting of sea ice and in the air over oceans accounts for almost $43 \%$ of the global heat accumulation, while the corresponding value for the land area is about $35 \%$ if $\sim 22 \%$ of land ice, which is mainly in Greenland, is treated separately.

It is concluded that net heat emissions contributes to $74 \%$ of global warming. The missing heat (26\%) must have other causes, e.g., the greenhouse effect, natural variations in the climate and/or the underestimation of net heat emissions.

The performed calculations are conservative, i.e., both the global heat accumulation and heat emissions are underestimated. Each of these means that the missing heat in Figure 4 is too high. These uncertainties are discussed in more detail in Appendix B.

Most measures that already have been taken to combat global warming are also beneficial for the current explanation. Renewable energy should be promoted instead of using fossil fuels. However, $\mathrm{CO}_{2}$ sequestration and subsequent storage will have very little effect on global warming. It is also concluded that nuclear power is not a solution to (but part of) the problem. The underestimated heat accumulation means that the missing heat in Figure 4 is too high. Also, the underestimation of net heat emission gives the same result. 


\section{Acknowledgements}

The performed research has depended on students who, over several years, made different substudies on this subject: Sergi Mas Miret (Global Heat Storage), Lara Nunes de Carvalho (Nuclear Tests), Ann-Marie Alakangas and Susanne Lamberg (Wars, Meteorites and Earthquakes), Nicolas Paget (Volcanos), Hubert Boulanger and Damien Orcel (Sea Level Rise), Dr. Jules Dim for his overview on the subject and Dr. Göran Hellström for valuable comments on the manuscript. Many of the performed substudies were repeated by even more students. The authors are most grateful to all of them.

\section{References}

Antonov, J.I., Levitus, S. and Boyer, T.P. (2002) 'Steric sea level variations during 1957-1994: importance of salinity', J. Geophys. Res., Vol. 107, No. C12, p.8013.

Broecker, W.S., Turekian, K.K. and Heezen, B.C. (1958) 'The relation of deep sea (Atlantic Ocean) sedimentation rates to variations in climate', American Journal of Science, Vol. 256, pp.503-517.

CDC (2007) 'The climate diagnosis center', http://www.cdc.noaa.gov/.

CDIAC (2007) 'US carbon dioxide information analysis center', http://www.cdiac.ornl.gov/.

Church, J.A., Gregory, J.M., Huybrechts, P., Kuhn, M., Lambeck, K., Nhuan, M.T., Qin, D., et al. (2001) 'Climate change 2001: the scientific basis', Chap. 11, Changes in Sea Level. 3rd Assessment Report of the IPCC, Cambridge: Cambridge Univ. Press.

EIA (2007) 'US energy information administration', http://www.eia.doe.gov/emeu/international.

Gervet, B. (2007) 'Heat emissions from gas flaring, coal fires, deforestation, and plastics', Luleå University of Technology, http://www.ltu.se/shb/2.1492/1.5035.

Global Gas Flaring Reduction (GGFR) (2007) The News Flare, http://www.worldbank.org/ggfr.

GulfLINK (2007) 'Office of the Special Assistant for Gulf War Illnesses', http://www .gulflink.osd.mil/.

Gutenberg, B. and Richter, C.F. (1956) 'Earthquake magnitude, intensity energy and acceleration', Bull. Seism. Soc. Am., Vol. 46, pp.105-145.

Harvey, L.D.D. (2000) Climate and Global Environmental Change, Harlow: Prentice Hall.

International Heat Flow Commission (IHFC) (2007) http://www.heatflow.und.edu/.

Ishii, M., Kimoto, M. and Kachi, M. (2003) 'Historical ocean subsurface temperature analysis with error estimates', Monthly Weather Review, Vol. 131, pp.51-73.

Johannessen, O.M., Bengtrsson, L., Miles, M., Kuzina, S., Semenov, V.A., Alekseev, G.V., Nagurnui, A.P., et al. (2003) 'Arctic climate change - observed and modeled temperature and sea ice variability', NERSC Technical Report No. 218.

Lawson, J.E. (1998) 'Oklahoma geological survey observatory catalogue of nuclear explosions', http://www.okgeosurvey1.gov/level2/nuke.cat.html.

Lyman, J.M., Willis, J.K. and Johnson, G.C. (2006) 'Recent cooling of the upper ocean', Geophys. Res. Letters, Vol. 33, L18604, doi:10.1029/2006GL027033.

Miller, L. and Douglas, B.C. (2006) 'On the rate and causes of twentieth century sea-level rise', Philos Transact a Math Phys Eng Sci., Vol. 364, pp.805-820.

National Snow and Ice Data Center (NSIDC) (2007a) 'Frozen ground data center', http://nsidc .org/fgdc/.

National Snow and Ice Data Center (NSIDC) (2007b) http://nsidc.org/data/seaice_index/.

NCDC-NOAA (2007) 'Global surface temperature anomalies', http://www.ncdc.noaa.gov/oa/ climate/research/anomalies/anomalies.html. 
Noerdlinger, P.D. and Brower, K.R. (2008) 'The melting of floating ice raises the ocean level', US NSIDC, http://nsidc.org/news/seaice/.

Permanent Service for Mean Sea Level (PSMSL) (2007) http://www.pol.ac.uk/psmsl/.

Pielke, R.A. (2005) 'Heat storage within the earth system', Forum, American Meteorological Society, pp.331-335.

Pielke, R.A., Davey, C. and Morgan, J.A. (2004) 'Assessing global warming with surface heat content', EOS. American Geophysical Union, Vol. 85, pp.210-211.

Pollak, H.N., Hurter, S.J. and Johansson, R.R. (1993) 'Heat flow from the Earth's interior: analysis of global data set', Reviews of Geophysics, Vol. 31, pp.267-280.

Salby, M.L. (1996) Fundamentals of Atmospheric Physics, New York: Academic Press.

Simkin, T. and Siebert, L. (1994) Volcanoes of the World, 2nd ed., Tucson: Geoscience Press/Smithsonian Inst. Global Volcanism Program.

Singh, P. and Singh, V.P. (2001) Snow and Glacier Hydrology, Dordrecht: Kluwer Academic Publishers.

Stockholm International Peace Research Institute (SIPRI) (2007) http://www.sipri.org.

Stracher, G.B. and Taylor, T.P. (2004) 'Coal fires burning out of control around the world: thermodynamic recipe for environmental catastrophe', International Journal of Coal Geology, Vol. 59, pp.7-17.

The World Bank (WB) (2007) 'Global gas flaring reduction initiative', Report 27235, World Bank Group, p.77, http://www.ifc.org/ogc/global_gas.htm.

U.S. Geological Survey (USGS) (2007) U.S. Geological Survey Earthquake Hazards Program, http://neic.usgs.gov/neis/eqlists/eqstats.html. 


\section{Appendix A}

\section{Methods used}

\section{Heat accumulation in ground}

It was assumed that the temperature of the ground surface was equal to the global LAT (see Figure 1) and that the mean thermal properties of the ground and geothermal heat flow are known. Because of the increasing ground surface temperature, heat is conducted from the ground surface into the ground.

The ground temperature change was determined by one-dimensional heat conduction:

$$
\frac{\partial^{2} \mathrm{~T}}{\partial \mathrm{z}^{2}}-\frac{1}{\alpha} \frac{\partial \mathrm{T}}{\partial \mathrm{t}}=0
$$

where:

$$
\begin{aligned}
\mathrm{T} & =\text { the ground temperature } \\
\mathrm{t} & =\text { time } \\
\lambda & =\text { the thermal conductivity of the ground } \\
\alpha & =\lambda / \mathrm{C}_{\mathrm{v}}=\text { the thermal diffusivity } \\
\mathrm{C}_{\mathrm{v}} & =\text { the volumetric heat capacity of the ground } \\
\mathrm{Z} & =\text { the vertical direction. }
\end{aligned}
$$

Equation (1) was numerically solved for $\mathrm{T}(\mathrm{z}=0)=\mathrm{LAT}(\mathrm{t})$ and $\mathrm{T}(\mathrm{z}=400)=\mathrm{C}$, a time step of $0.5 \mathrm{~h}$ during 120 years and a length step of $0.1 \mathrm{~m}$. A ground thermal conductivity of $2.5 \mathrm{~W} \mathrm{~m}^{-1} \mathrm{~K}^{-1}$, a volumetric heat capacity of $0.6 \mathrm{kWh} \mathrm{m}^{-3} \mathrm{~K}^{-1}$ and a geothermal heat flow of $0.065 \mathrm{~W} \mathrm{~m}^{-2}$ were assumed.

The resulting heat accumulation in the ground $(\mathrm{Q})$ caused by the temperature change $\Delta \mathrm{T}(\mathrm{z})$ after 120 years of global warming was calculated by:

$$
\mathrm{Q}_{\mathrm{g}}=\int_{\mathrm{D}}^{0} \mathrm{C}_{\mathrm{v}} \cdot \Delta \mathrm{T}(\mathrm{z}) \partial \mathrm{z}
$$

$\mathrm{D}$ is any depth at which the ground temperature is undisturbed by global warming. Equation (2) was solved for the boundary conditions used above. In the performed calculations, a sufficient $\mathrm{D}=400 \mathrm{~m}$ was used, since the temperature disturbance did not reach a depth below $270 \mathrm{~m}$.

\section{Heat accumulation in air}

In calculating the heat accumulation in air, its temperature profile was assumed to be linear from the ground surface to a height of $5500 \mathrm{~m}$, where the Earth's effective temperature occurs $\left(-18.8^{\circ} \mathrm{C}\right)$ (Salby, 1996). The mean relative humidity was assumed unchanged from 1880 to 2000 . It was estimated to be $62 \%$ after the area weighting of data for different latitudes (CDC, 2007). The calculations were separated into two air volumes, i.e., air over sea and land surface. The heat content of air (moist static energy) over the sea surface and land surface is expressed by:

$$
\mathrm{Q}_{\mathrm{a}}=\mathrm{A}_{\mathrm{s}} \int_{\mathrm{o}}^{\mathrm{H}} \mathrm{C}_{\mathrm{p}} \cdot \rho_{\mathrm{a}}(\mathrm{z}) \cdot \Delta \mathrm{T}_{\mathrm{s}}(\mathrm{z}) \partial \mathrm{z}+\mathrm{L} \cdot \Delta \mathrm{m}_{\mathrm{a}}(\mathrm{z}) \partial \mathrm{z}+\mathrm{A}_{1} \int_{\mathrm{o}}^{\mathrm{H}} \mathrm{C}_{\mathrm{p}} \cdot \rho_{\mathrm{a}}(\mathrm{z}) \cdot \Delta \mathrm{T}_{1}(\mathrm{z}) \partial \mathrm{z}+\mathrm{L} \cdot \Delta \mathrm{m}_{1}(\mathrm{z}) \partial \mathrm{z}
$$


where:

$$
\begin{aligned}
\mathrm{C} & =\text { the specific heat of dry air }\left(\mathrm{J} / \mathrm{kg},{ }^{\circ} \mathrm{C}\right) \\
\Delta \mathrm{T}\left({ }^{\circ} \mathrm{C}\right) & =\text { the air temperature change } \\
\mathrm{L} & =\text { the latent heat of vaporisation }(\mathrm{J} / \mathrm{kg}) \\
\Delta \mathrm{m} & =\text { the absolute humidity }\left(\mathrm{kg} / \mathrm{m}^{3}\right) .
\end{aligned}
$$

$A_{s}$ and $A_{1}=$ the sea surface area and land surface area.

\section{Heat required for ice melting}

The heat required to melt ice is also seen as a kind of heat accumulation. The performed calculations are based on the estimated volumes of melted land ice, sea ice and permafrost from 1880-2000. It was also assumed that melted ice is black ice, i.e., transparent ice with a density of $\rho_{\text {ice }}=917.3 \mathrm{~kg} / \mathrm{m}^{3}$ with a latent heat (melt heat) of $\mathrm{L}_{\mathrm{ice}}=334 \mathrm{~kJ} / \mathrm{kg}$. The total amount of energy required to melt $\mathrm{V}\left(\mathrm{m}^{3}\right)$ of ice is then given by:

$$
\mathrm{Q}_{\text {ice }}=\mathrm{V} \cdot \rho_{\text {ice }} \cdot \mathrm{L}_{\text {ice }} \cdot
$$

\section{Heat accumulation in sea water}

The heat accumulation in sea water is the total change in sensible heat, i.e., the heat required to warm up water. This heating is indirectly estimated from the volume expansion of heated water. The volume expansion $\Delta \mathrm{V}$ is given by:

$$
\Delta \mathrm{V}=\alpha \mathrm{V}_{\mathrm{o}} \Delta \mathrm{T}
$$

where $\alpha$ is the thermal coefficient of ocean with a salinity of $35 \mathrm{ppm}$. Since $\alpha$ is relatively linear, the estimated sea level increases as a result of thermal expansion $(\Delta \mathrm{V})$. Equation (5) gives the temperature increase $(\Delta \mathrm{T})$ of the sea water. The corresponding sensible heat accumulation in sea water $\left(\mathrm{Q}_{\mathrm{sw}}\right)$ is thus given by:

$$
\mathrm{Q}_{\mathrm{sw}}=\int_{0}^{1000} \mathrm{C} \cdot \Delta \mathrm{T}(\mathrm{z}) \partial \mathrm{z} .
$$

The total heat accumulation in sea water, $\mathrm{Q}_{\mathrm{s}}$, thus becomes:

$$
\mathrm{Q}_{\mathrm{s}}=\mathrm{Q}_{\mathrm{sw}}+\mathrm{Q}_{\mathrm{ice}} .
$$

\section{Total heat accumulation}

The total global heat accumulation is given by the sum of heat accumulation in the air, ground and seawater:

$$
\mathrm{Q}_{\text {total }}=\mathrm{Q}_{\mathrm{a}}+\mathrm{Q}_{\mathrm{g}}+\mathrm{Q}_{\mathrm{s}} \text {. }
$$




\section{Appendix B}

\section{Error estimation}

\section{Net heat generation}

The included net heat generation is reliable, i.e., all net heat included is really emitted (see Table 1). The major part, 'Commercial Energy Consumption', is as good as international energy statistics. 'Other nonrenewable heat' is underestimated since, e.g., underground coal fires were excluded and deforestation does not include the reduced biomass in normal forestland. The main uncertainty is in 'Miscellaneous Heat Sources' or, rather, heat emissions from earthquakes and volcanoes. Even though only few such rare events were included, it could be questioned if some of these should be seen as part of background heating, which means that they should not be included. Altogether, it is estimated that global heat emissions are underestimated by less than $10 \%$.

\section{Global heat accumulation}

The calculated heat accumulation in air is a reliable as the global temperature change reported by the US National Climatic Data Center (NCDC-NOAA, 2007). The heat accumulation into the ground is underestimated since the global mean value for the ground thermal conductivity was assumed at $2.5 \mathrm{~W} / \mathrm{m}, \mathrm{K}$, which corresponds to the crystalline bedrock from the ground surface and downwards. In areas with $10 \mathrm{~m}$ soil cover $(\sim 1 \mathrm{~W} / \mathrm{m}, \mathrm{K})$ or sedimentary bedrock, the resulting thermal conductivity would be $2.0 \mathrm{~W} / \mathrm{m}, \mathrm{K}$, which would reduce the total heat accumulation in the ground by $6.3 \%$. Heat absorbed by melting sea ice until 2000 was overestimated, since the melted ice area was assumed to have a mean thickness of $3 \mathrm{~m}$. In more recent studies, it was assumed that the thickness of the melted ice area was linearly thinner than 0 at the edge of the ice field. For that reason, the calculated mass of sea ice was too high, which reduces the total heat accumulation by $5.6 \%$ (Figure 3). The main uncertainty in this estimation concerns the sensible heat accumulation in sea water because of the various estimations and measurements of sea water temperature. In the current study, measurements (estimations) that give the sea water temperature over the longest period ( $\sim 50$ years) were chosen. Even though the warming of sea water is the main uncertainty in the performed calculations, the authors see no reliable way to estimate this error and this part is, therefore, left unchanged.

Assuming that this estimation of the uncertainty of used data is correct, the net heat generation would maximally be increased by $10 \%$ and the global heat accumulation decreased by $11.9 \%$. These maximum errors altogether reduce the amount of missing heat (unexplained heating) from $26 \%$ to $5.5 \%$, which means that almost all of global warming would be explained by net heat emissions. 